\title{
Prevalence of the EHI Groucho interaction motif in the metazoan Fox family of transcriptional regulators Sergey Yaklichkin ${ }^{1}$, Alexander Vekker ${ }^{2}$, Steven Stayrook ${ }^{3}$, Mitchell Lewis ${ }^{3}$ and Daniel S Kessler*1
}

\begin{abstract}
Address: ${ }^{1}$ Department of Cell and Developmental Biology, University of Pennsylvania School of Medicine, 1110 Biomedical Research Building II/ III, 421 Curie Boulevard, Philadelphia, PA 19104, USA, ${ }^{2}$ Department of Economics, University of Pennsylvania, 328 McNeil Building, 3718 Locust Walk, Philadelphia, PA 19104, USA and ${ }^{3}$ Department of Biochemistry and Biophysics, University of Pennsylvania School of Medicine, 813B Stellar-Chance Laboratories, 422 Curie Boulevard, Philadelphia, PA 19104, USA
\end{abstract}

Email: Sergey Yaklichkin - yaklichk@mail.med.upenn.edu; Alexander Vekker - avekker@ssc.upenn.edu; Steven Stayrook - stayrook@mail.med.upenn.edu; Mitchell Lewis - lewis@mail.med.upenn.edu;

Daniel S Kessler* - kesslerd@mail.med.upenn.edu

* Corresponding author

Published: 28 June 2007

BMC Genomics 2007, 8:20I doi:I0.|I86/|47|-2164-8-20|
Received: 21 December 2006

Accepted: 28 June 2007

This article is available from: http://www.biomedcentral.com/I47I-2I64/8/20I

(c) 2007 Yaklichkin et al; licensee BioMed Central Ltd.

This is an Open Access article distributed under the terms of the Creative Commons Attribution License (http://creativecommons.org/licenses/by/2.0), which permits unrestricted use, distribution, and reproduction in any medium, provided the original work is properly cited.

\begin{abstract}
Background: The Fox gene family comprises a large and functionally diverse group of forkhead-related transcriptional regulators, many of which are essential for metazoan embryogenesis and physiology. Defining conserved functional domains that mediate the transcriptional activity of Fox proteins will contribute to a comprehensive understanding of the biological function of Fox family genes.

Results: Systematic analysis of 458 protein sequences of the metazoan Fox family was performed to identify the presence of the engrailed homology-I motif (ehl), a motif known to mediate physical interaction with transcriptional corepressors of the TLE/Groucho family. Greater than $50 \%$ of Fox proteins contain sequences with high similarity to the ehl motif, including ten of the nineteen Fox subclasses (A, B, C, D, E, G, H, I, L, and Q) and Fox proteins of early divergent species such as marine sponge. The eh I motif is not detected in Fox proteins of the $F, J, K, M, N, O, P, R$ and $S$ subclasses, or in yeast Fox proteins. The ehI-like motifs are positioned C-terminal to the winged helix DNA-binding domain in all subclasses except for FoxG proteins, which have an $\mathrm{N}$-terminal motif. Two similar eh I-like motifs are found in the zebrafish FoxQI and in FoxG proteins of sea urchin and amphioxus. The identification of eh I-like motifs by manual sequence alignment was validated by statistical analyses of the Swiss protein database, confirming a high frequency of occurrence of ehl-like sequences in Fox family proteins. Structural predictions suggest that the majority of identified eh I-like motifs are short $\alpha$-helices, and wheel modeling revealed an amphipathicity that supports this secondary structure prediction.

Conclusion: A search for ehI Groucho interaction motifs in the Fox gene family has identified eh I-like sequences in greater than $50 \%$ of Fox proteins. The results predict a physical and functional interaction of TLE/Groucho corepressors with many members of the Fox family of transcriptional regulators. Given the functional importance of the eh I motif in transcriptional regulation, our annotation of this motif in the Fox gene family will facilitate further study of the diverse transcriptional and regulatory roles of Fox family proteins.
\end{abstract}




\section{Background}

DNA-binding transcriptional regulatory proteins have a modular structure and are composed of a sequence-specific DNA-binding domain and trans-regulatory domains. Multiple studies have shown that short conserved peptide regions mediate the biological functions of trans-regulatory domains. In the case of transcriptional repressors, such short protein regions can autonomously mediate repression when fused to a heterologous DNA-binding domain $[1,2]$. It appears that these conserved regions form either $\alpha$-helices or binding pockets to provide specific interacting surfaces for transcriptional corepressors. For instance, the Sin 3 interaction motif of NRSF/REST adopts a short amphipathic $\alpha$-helix that mediates specific physical interactions with the Sin 3 transcriptional corepressor [3]. In the present study, we focus on identifying and analyzing the Engrailed homology region-1 (eh1) transcriptional repression motif in the Fox gene family of forkhead-related transcriptional regulators. This motif is known to mediate specific physical interactions of a number of protein families with transcriptional corepressors of the TLE/Groucho protein family [4-7].

The eh1 motif is composed of eight amino acid residues with the sequence pattern FS(I/V)XXФФX, with X representing any non-polar or charged residue and $\Phi$ representing branched hydrophobic residues. The eh1 motif was originally identified as a conserved $\mathrm{N}$-terminal sequence shared between the Drosophila Engrailed protein and its vertebrate orthologs [6]. Functional analysis of the Engrailed protein has shown that the eh1 motif is required for active transcriptional repression in vivo, as well as for the physical interaction with Groucho corepressors $[7,8]$. An eh1-like motif was also identified in eight classes of the homeodomain protein superfamily (Emx, Dlx, Gsc, Hex, Msh, Six, Oct and Vnd) [5,9,10]. Further in vivo and in vitro studies have shown that the eh1like motif of Gsc, Nkx, Hex and Six is required for repression function in vivo by recruiting the TLE/Groucho corepressors $[5,9,11]$.

Eh1-like motifs have also been found in several members of the Fox family of forkhead-related transcriptional regulators [12]. Fox proteins are essential transcriptional regulators of embryogenesis, homeostasis, metabolism, and aging in metazoan organisms [13]. The highly conserved DNA-binding domain of Fox family proteins is characterized by the formation of three $\alpha$-helixes, three $\beta$-strands and two loops resembling wings [14], thus the winged helix DNA-binding domain (WHD) designation. The WHD is flanked by N-and C-terminal regions that share low similarity among the Fox protein subclasses. The initial classification of Fox proteins based on sequence-relatedness within the WHD established fifteen subclasses of the Fox gene family [15], and four additional Fox sub- classes were subsequently identified $[16,17]$. An updated list of Fox gene family members is available online [18].

Sequence analysis of several Fox proteins revealed that a short conserved C-terminal region of FoxA proteins (conserved region II or CII) was similar to the eh1 motif [12]. Further biochemical studies showed that FoxA2 physically interacts with TLE1, a mammalian Groucho protein, via the CII region [19]. These data suggest that the CII region not only resembles the eh1 motif in sequence, but also in the ability to directly binding Groucho/TLE corepressors. In addition, the Drosophila FoxG ortholog, Slp1, physically interacts with Groucho via an N-terminal eh1-like motif [20]. Furthermore, our recent studies in Xenopus have shown that FoxD3 can associate with the Xenopus Groucho ortholog, Grg4, via an eh1-like motif. The FoxD3 eh1 motif is essential for a functional interaction with $\mathrm{Grg} 4$ and for transcriptional repression in vivo [21]. These observations suggest an interaction of Groucho corepressors with multiple Fox family proteins, and prompted us to systematically examine all subclasses of the Fox gene family for the presence of eh1-like motifs. Given the functional importance of the eh1 motif in transcriptional regulation, annotation of the presence, pattern of distribution, and structural characteristics of this motif in the Fox gene family will facilitate further study of the diverse transcriptional and regulatory roles of Fox family proteins.

Here, we present a complete systematic analysis of the presence of eh1-like motifs in metazoan Fox proteins. Eh1-like motifs are identified in more than $50 \%$ of Fox proteins representing ten Fox family subclasses (A, B, C, D, G, E, H, I, L and Q) and statistical analyses of the Swiss protein database confirm a frequent occurrence of the motif in the Fox family. Secondary structure analysis of these Fox proteins predicts that the eh1-like motifs adopt a short amphipathic $\alpha$-helical structure. Taken together, the results point to a functional interaction of TLE/Groucho corepressors with many members of the Fox family and identify structural features of the eh1 motifs that will facilitate further study of the physical interaction of Fox proteins with TLE/Groucho corepressors.

\section{Results \\ Identification of eh I-like motifs in ten subclasses of the Fox gene family}

We performed a systematic analysis of 458 yeast and metazoan protein sequences belonging to nineteen subclasses of the Fox family of transcriptional factors for the presence of eh1-like motifs. An initial manual search was conducted for the presence of sequences composed of eight amino acids with a highly conserved hydrophobic core matching the eh1 motif pattern of FSФХХФФХ (X, non-polar or charged residue; $\Phi$, branched hydrophobic 
residue). Conserved regions of aligned orthologous Fox protein sequences were examined for homology to the eh1 consensus sequence. Eh1-like motifs were identified in Fox protein sequences of 10 subclasses, including the $A$, B, C, D, E, G, H, I, L and Q, but not in Fox proteins of the F, J, K, M, N, O, P, R and S subclasses (Table 1). Fox proteins containing an eh1-like motif were found across multiple animal phyla, and included chordates, hemichordates, and a variety of invertebrates, but not yeast (Tables 2 and 3). The identified motifs exhibit high similarity to the Drosophila eh1 motif in the range of 50$87 \%$. To summarize the results, a phylogenetic tree for the Fox gene family was constructed in which the presence of an eh1-like motif within individual Fox proteins is indicated [see Additional files 1 and 2].

To validate the results of the manual search for eh1-like motifs, we used the expectation-maximization algorithm in the MEME program [22]. We initially examined 18 FoxD3-related protein sequences, which contain a conserved and functional eh1 motif [21]. As predicted, the analysis identified eh1-like motifs (E-value of 10-75) at 18 sites corresponding to the previously described eh 1 motif of FoxD3. When this approach was extended to the entire Fox family of 458 proteins, eh1-like motifs were identified at 213 sites in ten Fox subclasses (E-value of $<10-16$ ). The eh1-like motifs identified using the expectation-maximization algorithm corresponded to motifs identified in the manual sequence analysis, as well as to motifs previously identified in the Fox family $[12,23]$.
To confirm the statistical significance of the match between identified eh1-like sequences and the eh1 consensus, a hidden Markov model (HMM) was constructed [24] for the eh1 motif of FoxD3 (eh1 FD3). This model of the eh1 motif was used to search the SWISS protein database and a summary of the results of the eh1 FD3 HHM analysis is shown in Table 4. A total of 49,363 matches with the eh1 motif were identified, and 647 matches were to proteins that are members of transcription factor families. The mean log-odds score for all transcriptional proteins was 9.07, whereas non-transcriptional proteins scored at 6.87 . Among transcriptional proteins, Fox family proteins resulted in the strongest matches with the eh1 motif, with a mean log-odds scores of 14.34 . The motifs were identified in 9 subclasses of the Fox protein family which included A, B, C, D, E, G, H, L and Q (the FoxI subclass is not represented in the current SWISS protein database). The search also identified a significant number of high scoring matches (mean log-odds score of 11.61) for homeodomain-containing proteins of the para-Hox cluster [25], but the score for other non-Fox, non-para-Hox transcriptional proteins was low (7.72). The results of the HMM analysis strongly supports the conclusion that eh1like motifs are present within proteins of the Fox family at high frequency when compared with most transcriptional protein families and non-transcriptional proteins.

To evaluate the statistical significance of the eh1-like motif identification results obtained by HMM, logistic regression analysis was performed. Analysis of the logodds scores for the transcriptional protein and non-tran-

Table I: Occurrence of eh I-like motifs in the Fox subclasses.

\begin{tabular}{|c|c|c|c|}
\hline Fox subclass & Total number of proteins ${ }^{a}$ & Number of eh I-postive proteins ${ }^{b}$ & Number of eh I-negative proteins \\
\hline$A$ & 39 & 37 & 2 \\
\hline B & 40 & 40 & 0 \\
\hline C & 27 & 24 & 3 \\
\hline $\mathrm{D}$ & 74 & 55 & 19 \\
\hline $\mathrm{E}$ & 22 & 15 & 7 \\
\hline $\mathrm{F}$ & 19 & 0 & 19 \\
\hline G & 21 & 21 & 0 \\
\hline $\mathrm{H}$ & 14 & 11 & 3 \\
\hline 1 & 25 & 5 & 20 \\
\hline J & 29 & 0 & 29 \\
\hline K & 15 & 0 & 15 \\
\hline L & 21 & 6 & 15 \\
\hline$M$ & 9 & 0 & 9 \\
\hline $\mathrm{N}$ & 26 & 0 & 26 \\
\hline 0 & 8 & 0 & 8 \\
\hline$P$ & 25 & 0 & 25 \\
\hline $\mathrm{Q}$ & 26 & 26 & 0 \\
\hline$R$ & 13 & 0 & 13 \\
\hline$S$ & 5 & 0 & 5 \\
\hline
\end{tabular}

a Number of proteins from each Fox subclass analyzed for the presence of an eh I-like motif.

b Proteins containing a sequence with at least $50 \%$ similarity to the eh I motif of the Drosophila engrailed homeodomain protein [7]. 
Table 2: List of the identified eh I-like motifs in eight subclasses of invertebrate Fox proteins.

\begin{tabular}{|c|c|c|c|c|c|c|c|}
\hline Subclass & Protein & Motifs $^{a}$ & Homology to eh I motifb & Positionc & Protein length & Species & Accession number \\
\hline \multicolumn{8}{|l|}{ A } \\
\hline & FoxA & FAIKNIIA & $62.5 \%$ & $243-250$ & 321 & H. vulgaris & AAO92606 \\
\hline & FoxA & FAIKNIIA & $62.5 \%$ & $215-222$ & 286 & $N$. vectensis & $4237484 I$ \\
\hline & FoxA & FSIDRIMH & $50 \%$ & $4 \mid 2-419$ & 485 & D. japonica & 9309317 \\
\hline & FoxA & FSITRLLP & $75 \%$ & $302-309$ & 350 & H. armigera & 57791692 \\
\hline & FoxA & FSITNLMS & $62.5 \%$ & $375-382$ & 435 & P. vulgata & 22859616 \\
\hline & FoxA & FSITRLLP & $62.5 \%$ & $300-307$ & 349 & B. mori & II298368| \\
\hline & FoxA & FSITRLLP & $62.5 \%$ & $372-379$ & 435 & A. aegypti & 108881332 \\
\hline & FoxA & FSITRLLP & $62.5 \%$ & $374-381$ & 437 & A. gambiae & 55233684 \\
\hline & FoxA & FSINRLLP & $62.5 \%$ & $452-459$ & 510 & D. melangaster & 7301684 \\
\hline & FoxA & FSINRLLP & $62.5 \%$ & $370-377$ & 431 & T. castaneum & 86515352 \\
\hline & FoxA & FSITRLLP & $75 \%$ & $460-467$ & 570 & A. mellifera & II 0759792 \\
\hline & FoxA & FSINSIIP & $62.5 \%$ & $377-384$ & 440 & S. purpuratus & 91983614 \\
\hline & FoxA5 & FSISSLMN & $62.5 \%$ & $452-459$ & 587 & C. intestinalis & AAB6 I 227 \\
\hline & FoxA5 & FSISNLMS & $87.5 \%$ & $342-349$ & 403 & B. floridae & CAA65368 \\
\hline & FoxA5 & FSISSLMN & $62.5 \%$ & $44 I-448$ & 567 & M. oculata & AAB69278 \\
\hline \multicolumn{8}{|l|}{ B } \\
\hline & FoxB & FAIENLIG & $62.5 \%$ & $151-158$ & 262 & $N$. vectensis & ABA03229 \\
\hline & FoxB & FSIESILS & $75 \%$ & $229-236$ & 237 & C. elegans & AAA28I 04.1 \\
\hline & FoxB & FTIESLIT & $75 \%$ & $222-229$ & 372 & D. melangaster & I 7977684 \\
\hline & FoxB & FTIESLIT & $75 \%$ & $172-179$ & 241 & T. castaneum & 91082601 \\
\hline & FoxB & FTIESLIT & $75 \%$ & $189-196$ & 198 & A. gambiae & EAA07672 \\
\hline & FoxB & FTIENIIA & $75 \%$ & $313-320$ & 365 & A. mellifera & $110759 \mid 34$ \\
\hline & FoxB & FTIENIIS & $87.5 \%$ & $187-194$ & 360 & S. purpuratus & NP999797 \\
\hline & FoxB & FSIENIIS & $87.5 \%$ & $305-312$ & 475 & C. intestinalis & CAD58964 \\
\hline & FoxB & FNIENIIA & $62.5 \%$ & $|8|-\mid 88$ & 289 & B. floridae & CAD44627 \\
\hline \multicolumn{8}{|l|}{ C } \\
\hline & FoxC & FTVDSLMN & $50 \%$ & $260-267$ & 508 & D. melangaster & 17975538 \\
\hline & FoxC & FTVDSLMN & $50 \%$ & $266-273$ & 496 & A. gambiae & EAAII 1069 \\
\hline & FoxC & FTVDSLMN & $50 \%$ & $25 I-258$ & 412 & A. aegypti & 108876322 \\
\hline & FoxC & FSVDALMN & $50 \%$ & $304-311$ & 495 & A. mellifera & 110758357 \\
\hline & FoxC & YTVDSLMA & $50 \%$ & $258-265$ & 479 & S. purpuratus & $72007 \mid 14$ \\
\hline & FoxC & FSVDNIMT & $75 \%$ & $233-300$ & 497 & B. floridae & 57337372 \\
\hline \multicolumn{8}{|l|}{$D$} \\
\hline & FoxD & FMISNLLK & $75 \%$ & $434-44 \mid$ & 444 & S. domuncula & CAE5I 209 \\
\hline & FoxD & FSMESILS & $62.5 \%$ & $3-10$ & 333 & C. elegans & 17536629 \\
\hline & FoxD & FSISHIIS & $87.5 \%$ & $393-400$ & 455 & D. japonica & BACI0918 \\
\hline & FoxD & FRIETLIG & $50 \%$ & $435-442$ & 456 & D. melangaster & $|764742|$ \\
\hline & FoxD & FSIENLIG & $75 \%$ & $491-498$ & 504 & A. aegypti & 10886922 \\
\hline & FoxD & FSIDALIG & $62.5 \%$ & $313-320$ & 354 & A. mellifera & II 0759337 \\
\hline & FoxD & FTIDSLLN & $62.5 \%$ & $308-315$ & 401 & S. purpuratus & II595303| \\
\hline
\end{tabular}


Table 2: List of the identified eh I-like motifs in eight subclasses of invertebrate Fox proteins. (Continued)

\begin{tabular}{|c|c|c|c|c|c|c|c|}
\hline & FoxD & FSIESLIG & $62.5 \%$ & $377-384$ & 506 & C. savignyi & BAB68347 \\
\hline & FoxD & FSIENIIG & $75 \%$ & $311-318$ & 402 & B. floridae & AF5I 2537 \\
\hline \multicolumn{8}{|l|}{$E$} \\
\hline & FoxE & FSIENIIG & $75 \%$ & $207-2 \mid 4$ & 393 & C. intestinalis & BAC57420 \\
\hline & FoxE4 & FSIDNIIA & $75 \%$ & $227-234$ & 381 & B. floridae & 18653452 \\
\hline \multicolumn{8}{|l|}{ G } \\
\hline & FoxG & FSIENILK & $75 \%$ & $12-19$ & 318 & M. leidyi & AANI 7798 \\
\hline & FoxG & FSIRQMLD & $50 \%$ & $16-23$ & 260 & D. japonica & BACI0917 \\
\hline & FoxG & FSILDLCP & $37.5 \%$ & $4-11$ & 270 & C. elegans & 17569837 \\
\hline & FoxG & FSINSILP & $50 \%$ & $18-25$ & 424 & A. gambiae & EAA43390 \\
\hline & FoxG & FGMDRLLG & $37.5 \%$ & $284-291$ & 424 & A. gambiae & EAA43390 \\
\hline & FoxG & FSISSILP & $75 \%$ & $156-163$ & 444 & T. castaneum & 91080905 \\
\hline & FoxG & FNMERLLA & $37.5 \%$ & $38 I-388$ & 444 & T. castaneum & 91080905 \\
\hline & FoxGI & FSIRSILP & $62.5 \%$ & $5 I-58$ & 451 & A. mellifera & 110756018 \\
\hline & FoxGI & FSMERLLQ & $37.5 \%$ & $328-335$ & 451 & A. mellifera & 110756018 \\
\hline & FoxGI & FSIDAILA & $62.5 \%$ & $12-19$ & 322 & D. melangaster & CAA46890 \\
\hline & FoxG2 & FSIDAILP & $62.5 \%$ & $62-69$ & 445 & D. melangaster & CAA4689I.I \\
\hline & FoxG & FSVESMLS & $62.5 \%$ & $34-41$ & 507 & S. purpuratus & 72179617 \\
\hline & FoxG & FSVERLLS & $75 \%$ & $396-403$ & 507 & S. purpuratus & 72179617 \\
\hline & FoxGI & FSIRRMLS & $62.5 \%$ & $20-27$ & 402 & B. floridae & AF067203 \\
\hline & FoxGI & FSVERLLS & $75 \%$ & $286-293$ & 402 & B. floridae & AF067203 \\
\hline \multicolumn{8}{|l|}{ L } \\
\hline & FoxLI & FTIDNIIG & $75 \%$ & $356-363$ & 365 & D. melangaster & Q02360 \\
\hline & FoxLI & FSIDNILA & $75 \%$ & $299-306$ & 521 & S. purpuratus & 72009133 \\
\hline \multicolumn{8}{|l|}{$\mathrm{Q}$} \\
\hline & FoxQI & FSIDSILG & $62.5 \%$ & $25 I-258$ & 408 & S. purpuratus & 82706210 \\
\hline & FoxQI & FSIESILS & $75 \%$ & $268-275$ & 385 & C. intestinalis & 70569660 \\
\hline & FoxQI & FSIDAILS & $75 \%$ & $226-233$ & 324 & B. floridae & $\mathrm{CAH} 5583 \mathrm{I}$ \\
\hline & FoxQ2b & FDVESLLR & $50 \%$ & $282-289$ & 380 & C. hemisphaerica & 108796163 \\
\hline & FoxQ2a & FSIENILG & $75 \%$ & $325-332$ & 387 & C. hemisphaerica & $108796|6|$ \\
\hline & FoxQ2 & FTIEAILE & $62.5 \%$ & $221-228$ & 230 & C. elegans & 17505695 \\
\hline & FoxQ2 & FDVASLLA & $50 \%$ & $348-355$ & 599 & D. melangaster & $6657 \mid 262$ \\
\hline & FoxQ2 & FDVASLLA & $50 \%$ & $233-240$ & 299 & T. castaneum & 91076112 \\
\hline & FoxQ2 & FDVESLLR & $50 \%$ & $232-239$ & 307 & A. gambiae & XP566358 \\
\hline & FoxQ2 & FSIENLAQ & $62.5 \%$ & $4-11$ & 329 & S. purpuratus & ABB89473 \\
\hline & FoxQ2 & FSIDRLVG & $62.5 \%$ & $4-11$ & 271 & B. floridae & AYI63864 \\
\hline \multicolumn{8}{|l|}{ Orphans } \\
\hline & Foxl & FRIEFLLK & $50 \%$ & $276-283$ & 285 & N. vectensis & ABA03228 \\
\hline & Foxl & FSISKLIL & $75 \%$ & $211-218$ & 218 & S. domuncula & CAE5I2I3 \\
\hline
\end{tabular}

a The highly conserved core of the ehI-like motifs are indicated in bold.

$\mathrm{b}$ The percent similarity between the identified Fox eh I-like motifs and the ehI motif (FSISNILS) of the Drosophila engrailed homeodomain protein [7].

c The location of the motifs within the amino acid sequence of the individual Fox proteins. 
Table 3: List of the identified eh I-like motifs in ten subclasses of chordate Fox proteins.

\begin{tabular}{|c|c|c|c|c|c|c|c|}
\hline Subclass & Protein & Motifa & Homology to eh I motif & Positionc & Protein length & Species & Accession \\
\hline \multicolumn{8}{|l|}{$A$} \\
\hline & FoxAl & FSINNLMS & $75 \%$ & $359-366$ & 427 & D. rerio & AAH65668 \\
\hline & FoxAla & FSINNLMS & $75 \%$ & $356-363$ & 428 & X. laevis & AAN7633I \\
\hline & FoxAlb & FSINNLMS & $75 \%$ & $355-362$ & 427 & X. laevis & AAAI7050 \\
\hline & FoxAl & FSINNLMS & $75 \%$ & $394-401$ & 466 & R. norvegicus & 6981034 \\
\hline & FoxAl & FSINNLMS & $75 \%$ & $396-403$ & 468 & M. musculus & P35582 \\
\hline & FoxAl & FSINNLMS & $75 \%$ & $400-407$ & 472 & H. sapiens & 24497501 \\
\hline & FoxA2 & FSINNLMS & $75 \%$ & $342-349$ & 409 & D. rerio & 18858687 \\
\hline & FoxA2a & FSINNLMS & $75 \%$ & $35 I-358$ & 434 & X. laevis & 45361699 \\
\hline & FoxA2 & FSINNLMS & $75 \%$ & $354-361$ & 438 & G. gallus & NP990I0I \\
\hline & FoxA2 & FSINNLMS & $75 \%$ & $377-384$ & 459 & M. musculus & 6753898 \\
\hline & FoxA2 & FSINNLMS & $75 \%$ & $376-383$ & 458 & R. norvegicus & NP036875 \\
\hline & FoxA2 & FSINNLMS & $75 \%$ & $376-383$ & 457 & H. sapiens & 24497504 \\
\hline & FoxA3 & FSITNLMS & $87.5 \%$ & $376-383$ & 441 & D. rerio & 18858689 \\
\hline & FoxA3 & FSITNLMS & $87.5 \%$ & $259-266$ & 324 & S. salar & AACI6333 \\
\hline & FoxA3 & FSINNLMS & $75 \%$ & $307-314$ & 353 & M. musculus & 22477526 \\
\hline & FoxA3 & FSINNLMS & $75 \%$ & $394-401$ & 466 & R. norvegicus & CAA394I8. \\
\hline & FoxA3 & FSINNLMS & $75 \%$ & $304-311$ & 350 & H. sapiens & 24497506 \\
\hline & FoxA4 & FSITNLMS & $87.5 \%$ & $345-352$ & 417 & A. mexicanum & AAC 60128 \\
\hline & FoxA4a & FSITQLMS & $75 \%$ & $328-335$ & 399 & $X$. laevis & CAA46290 \\
\hline & FoxA4b & FSITQLMS & $75 \%$ & $328-335$ & 400 & X. laevis & AAB22027 \\
\hline & FoxA5 & FSISSLMN & $62.5 \%$ & $452-459$ & 587 & C. intestinalis & $A A B 61227$ \\
\hline & FoxA5 & FSISNLMS & $87.5 \%$ & $342-349$ & 403 & B. floridae & CAA65368 \\
\hline & FoxA5 & FSISSLMN & $62.5 \%$ & $44 I-448$ & 567 & M. oculata & AAB69278 \\
\hline \multicolumn{8}{|l|}{ B } \\
\hline & FoxB & FSIENIIS & $87.5 \%$ & $305-312$ & 475 & C. intestinalis & CAD58964 \\
\hline & FoxB & FNIENIIA & $62.5 \%$ & $|8|-188$ & 289 & B. floridae & CAD44627 \\
\hline & FoxBI & FAIENIIA & $62.5 \%$ & $|64-17|$ & 297 & D. rerio & AAH56754 \\
\hline & FoxBI & FAIESIIA & $62.5 \%$ & $|7|-\mid 78$ & 289 & T. nigroviridis & 47209343 \\
\hline & FoxBI & FAIENIIA & $62.5 \%$ & $167-174$ & 319 & X. laevis & AAC62623 \\
\hline & FoxBla & FAIENIIA & $62.5 \%$ & $170-177$ & 325 & M. musculus & Q64732 \\
\hline & FoxBlb & FAIENIIA & $62.5 \%$ & $169-176$ & 324 & M. musculus & $\times 92592$ \\
\hline & FoxBI & FAIENIIA & $62.5 \%$ & $170-178$ & 324 & H. sapiens & Q99853 \\
\hline & FoxB2 & FAIENIIG & $62.5 \%$ & $176-183$ & 317 & X. laevis & CAD31848 \\
\hline & FoxB2 & FAIENIIG & $62.5 \%$ & $267-274$ & 428 & M. musculus & NP032049 \\
\hline & FoxB2 & FAIENIIG & $62.5 \%$ & $266-273$ & 425 & R. norvegicus & 109459945 \\
\hline & FoxB2 & FAIENIIG & $62.5 \%$ & $270-277$ & 432 & H. sapiens & 61966923 \\
\hline \multicolumn{8}{|l|}{ C } \\
\hline & FoxC & FSVDNIMT & $75 \%$ & $233-300$ & 497 & B. floridae & 57337372 \\
\hline & FoxCl.I & FSVDNIMT & $62.5 \%$ & $277-284$ & 476 & D. rerio & AF219949 \\
\hline & FoxCl.2 & FSMDTIMT & $75 \%$ & $254-261$ & 433 & D. rerio & AF219950 \\
\hline & FoxCl & FSMDTIMT & $75 \%$ & $275-282$ & 470 & T. nigroviridis & 47220394 \\
\hline & FoxCl & FSVDNIMT & $75 \%$ & $298-305$ & 495 & X. laevis & 80478512 \\
\hline & FoxCl & FSVDNIMT & $75 \%$ & $275-282$ & 528 & G. gallus & CAA7685I \\
\hline & FoxCl & FSVDNIMT & $75 \%$ & $308-315$ & 553 & M. musculus & AAH520II \\
\hline
\end{tabular}


Table 3: List of the identified eh I-like motifs in ten subclasses of chordate Fox proteins. (Continued)

\begin{tabular}{|c|c|c|c|c|c|c|c|}
\hline & FoxCl & FSVDNIMT & $75 \%$ & $307-314$ & 502 & B. taurus & 76639995 \\
\hline & $\mathrm{FoxCla}$ & FSVDNIMT & $75 \%$ & $308-315$ & 553 & H. sapiens & Q12948 \\
\hline & FoxClb & FSVDNIMT & $75 \%$ & $308-315$ & 553 & H. sapiens & AAC72915 \\
\hline & FoxC2 & FSVENIMT & $75 \%$ & $258-265$ & 463 & X. laevis & 47497986 \\
\hline & FoxC2 & FSVENIMT & $75 \%$ & $244-251$ & 445 & G. gallus & AAC 60065 \\
\hline & FoxC2 & FSVETIMT & $75 \%$ & $269-276$ & 494 & M. musculus & Q61850 \\
\hline & FoxC2 & FSVENIMT & $75 \%$ & $270-277$ & 501 & H. sapiens & Q99958 \\
\hline \multicolumn{8}{|c|}{$\mathrm{D}$} \\
\hline & FoxD & FSIESLIG & $62.5 \%$ & $377-384$ & 506 & C. savignyi & BAB68347 \\
\hline & FoxD & FSIENIIG & $75 \%$ & $311-318$ & 402 & B. floridae & AF5 I 2537 \\
\hline & FoxDI & FSIDNIIG & $75 \%$ & $295-302$ & 363 & D. rerio & AAH75922 \\
\hline & FoxDI.I & FSIDSIIG & $62.5 \%$ & $277-284$ & 343 & D. rerio & 45501117 \\
\hline & FoxDI & FSIESIIG & $62.5 \%$ & 294-301 & 345 & X. laevis & 3892202 \\
\hline & FoxDI & FSIESIIG & $62.5 \%$ & $377-384$ & 440 & G. gallus & AAB08467 \\
\hline & FoxDI & FSIESLIG & $62.5 \%$ & $364-371$ & 455 & R. norvegicus & XP00I057782 \\
\hline & FoxDI & FSIESLIG & $62.5 \%$ & $365-372$ & 456 & M. musculus & AAC42042 \\
\hline & FoxDI & FSIESIIG & $62.5 \%$ & $362-369$ & 465 & H. sapiens & Q16676 \\
\hline & FoxD2 & FSIDNIIG & $75 \%$ & $276-283$ & 346 & X. laevis & CAC69867 \\
\hline & FoxD2 & FSIDNIIG & $75 \%$ & $365-372$ & 443 & G. gallus & AAC 60064 \\
\hline & FoxD2 & FSIDHIMG & $62.5 \%$ & $409-416$ & 492 & M. musculus & NP032619 \\
\hline & FoxD2 & FSIDHIMG & $62.5 \%$ & $412-419$ & 495 & H. sapiens & 55956928 \\
\hline & FoxD3 & FSIENIIG & $75 \%$ & $297-304$ & 371 & D. rerio & AAC06366 \\
\hline & FoxD3a & FSIENIIG & $75 \%$ & $297-304$ & 371 & X. laevis & CACI2963 \\
\hline & FoxD3b & FSIENIIG & $75 \%$ & $297-304$ & 371 & X. laevis & $\mathrm{CACI} 2895$ \\
\hline & FoxD3 & FSIENIIG & $75 \%$ & $319-326$ & 394 & G. gallus & AAC60066 \\
\hline & FoxD3 & FSIENIIG & $75 \%$ & $366-373$ & 469 & M. musculus & NMOI0425 \\
\hline & FoxD3 & FSIENIIG & $75 \%$ & $378-385$ & 478 & H. sapiens & NP0363I5 \\
\hline & FoxD4 & FSIESIMQ & $62.5 \%$ & $324-331$ & 408 & H. sapiens & 18959276 \\
\hline & FoxD4 & FTIESIMQ & $62.5 \%$ & $320-327$ & 444 & M. musculus & 6679841 \\
\hline & FoxD5 & FSIDSIMA & $62.5 \%$ & $254-261$ & 321 & D. rerio & NP57I345 \\
\hline & FoxD5a & FSIENIMR & $62.5 \%$ & $285-292$ & 352 & X. laevis & AAD478II \\
\hline & FoxD5b & FSIENIMK & $62.5 \%$ & $285-292$ & 353 & X. laevis & CAB44729 \\
\hline & FoxD5c & FSIENIMG & $62.5 \%$ & $28 I-288$ & 342 & X. laevis & CAB44730 \\
\hline \multicolumn{8}{|c|}{$E$} \\
\hline & FoxE & FSIENIIG & $75 \%$ & $207-2 \mid 4$ & 393 & C. intestinalis & BAC57420 \\
\hline & FoxEI & FRINSLIG & $62.5 \%$ & $202-209$ & 354 & D. rerio & XP696065 \\
\hline & FoxEI & FRINNLIG & $62.5 \%$ & $206-213$ & 363 & T. nigroviridis & $472 \mid 4250$ \\
\hline & FoxEI & FSINTLIG & $62.5 \%$ & $231-238$ & 379 & X. laevis & 46198238 \\
\hline & FoxE3 & FSIDNIIS & $87.5 \%$ & $269-276$ & 422 & D. rerio & 118918391 \\
\hline & FoxE3 & FSIDSLIN & $62.5 \%$ & $215-222$ & 365 & X. laevis & 6642989 \\
\hline & FoxE3 & FSIDSLIS & $62.5 \%$ & $239-246$ & 383 & G. galus & 118094619 \\
\hline & FoxE3 & FRLDSLLG & $50 \%$ & $195-202$ & 288 & M. musculus & 7657098 \\
\hline & FoxE3 & FSVDSLVP & $50 \%$ & $179-186$ & 385 & C. familiaris & 73977761 \\
\hline & FoxE3 & FSVDSLVN & $50 \%$ & $217-224$ & 319 & H. sapiens & CAII 4973 \\
\hline & FoxE3 & FRLDSLLG & $50 \%$ & $193-200$ & 286 & R. norvegicus & XP233428 \\
\hline & FoxE4 & FSIDNIIA & $75 \%$ & $227-234$ & 381 & B. floridae & 18653452 \\
\hline \multicolumn{8}{|c|}{ G } \\
\hline & FoxGI & FSIRRMLS & $62.5 \%$ & $20-27$ & 402 & B. floridae & AF067203 \\
\hline
\end{tabular}


Table 3: List of the identified eh I-like motifs in ten subclasses of chordate Fox proteins. (Continued)

\begin{tabular}{|c|c|c|c|c|c|c|c|}
\hline & FoxGI & FSVERLLS & $75 \%$ & $286-293$ & 402 & B. floridae & AF067203 \\
\hline & FoxGI & FSINSLVP & $62.5 \%$ & $18-25$ & 420 & D. rerio & 18858707 \\
\hline & FoxGI & FSINSLMP & $62.5 \%$ & $18-25$ & 436 & X. laevis & AAC7950I \\
\hline & FoxGI & FSINSLVP & $62.5 \%$ & $18-25$ & 451 & G. gallus & U47275 \\
\hline & FoxGI & FSINSLVP & $62.5 \%$ & $18-25$ & 481 & M. musculus & AAB42। 58 \\
\hline & FoxGI & FSINSLVP & $62.5 \%$ & $18-25$ & 480 & R. norvegicus & 6978845 \\
\hline & FoxGla & FSINSLVP & $62.5 \%$ & $18-25$ & 469 & H. sapiens & CAA55038 \\
\hline & FoxGIb & FSINSLVP & $62.5 \%$ & $18-25$ & 477 & H. sapiens & $X 74142$ \\
\hline \multicolumn{8}{|l|}{$\mathrm{H}$} \\
\hline & FoxHI & FAIDSLLH & $50 \%$ & $250-257$ & 472 & D. rerio & 18858709 \\
\hline & FoxHI & FAIDSLLH & $50 \%$ & $278-285$ & 285 & T. nigroviridis & 47223489 \\
\hline & FoxHI & FMIDSLLH & $50 \%$ & $27 I-278$ & 518 & X. laevis & P70056 \\
\hline & FoxHI & FSIKSLLG & $62.5 \%$ & $198-205$ & 401 & R. norvegicus & XP235454 \\
\hline & FoxHI & FSIKSLLG & $62.5 \%$ & $167-174$ & 310 & B. taurus & CAD58794 \\
\hline & FoxHI & FSIKSLLG & $62.5 \%$ & $198-205$ & 401 & M. musculus & 6679845 \\
\hline & FoxHI & FSIKSLLG & $62.5 \%$ & $|94-20|$ & 612 & H. sapiens & 41107639 \\
\hline \multicolumn{8}{|l|}{ I } \\
\hline & Foxll & FSVNNLIY & $75 \%$ & $405-412$ & 419 & D. rerio & AAO63568 \\
\hline & Foxllc & FSVNSLIY & $62.5 \%$ & $367-374$ & 381 & X. laevis & CAD3। 849 \\
\hline & Foxllc & FTVNSLIY & $62.5 \%$ & $345-352$ & 359 & G. gallus & 50747424 \\
\hline & Fox 12 & FSVNSLIY & $62.5 \%$ & $369-376$ & 383 & D. rerio & AAP92808 \\
\hline \multicolumn{8}{|c|}{ Q } \\
\hline & FoxQI & FSIESILS & $75 \%$ & $268-275$ & 385 & C. intestinalis & 70569660 \\
\hline & FoxQI & FSIDAILS & $75 \%$ & $226-233$ & 324 & B. floridae & CAH5583I \\
\hline & FoxQI & FAIDSILS & $62.5 \%$ & $177-184$ & 383 & D. rerio & AAH67I39 \\
\hline & FoxQI & FRIDSLLS & $62.5 \%$ & $276-283$ & 383 & D. rerio & AAH67I39 \\
\hline & FoxQI & FTIDSILS & $75 \%$ & $196-203$ & 272 & T. nigroviridis & 47220396 \\
\hline & FoxQI & FAIDSILS & $62.5 \%$ & $224-231$ & 381 & X. laevis & 76152394 \\
\hline & FoxQI & FAIDSILS & $62.5 \%$ & $268-275$ & 400 & M. musculus & 31560693 \\
\hline & FoxQI & FAIDSILS & $62.5 \%$ & $252-259$ & 439 & R. norvegicus & 12408312 \\
\hline & FoxQI & FAIDSILR & $50 \%$ & $270-277$ & 402 & H. sapiens & 8489093 \\
\hline & FoxQ2 & FTIDYLLY & $62.5 \%$ & $17-24$ & 244 & D. rerio & XP694I56 \\
\hline & FoxQ2 & FTIDYLLF & $62.5 \%$ & $20-27$ & 210 & T. nigroviridis & 47209212 \\
\hline & FoxQ2 & FSIDRLVG & $62.5 \%$ & $4-110$ & 271 & B. floridae & AYI63864 \\
\hline \multicolumn{8}{|l|}{ L } \\
\hline & FoxLI & FSIDSILS & $75 \%$ & $284-291$ & 363 & D. rerio & 41055835 \\
\hline & FoxLI & FSIDSILA & $62.5 \%$ & $255-262$ & 336 & M. musculus & NP032050 \\
\hline & FoxLI & FSIDSILA & $62.5 \%$ & $259-266$ & 389 & R. norvegicus & 109508994 \\
\hline & FoxLI & FSIDSILA & $62.5 \%$ & $262-269$ & 346 & B. taurus & 61823329 \\
\hline & FoxLI & FSIDSILA & $62.5 \%$ & $272-279$ & 356 & C. familiaris & 73956953 \\
\hline & FoxLI & FSIDSILA & $62.5 \%$ & $26 I-268$ & 245 & H. sapiens & 22779860 \\
\hline
\end{tabular}

a The highly conserved core of the eh I-like motifs are indicated in bold.

b The percent similarity between the identified Fox ehI-like motifs and the ehI motif (FSISNILS) of the Drosophila engrailed homeodomain protein [7].

cThe location of the motifs within the amino acid sequence of the individual Fox proteins. 
Table 4: Descriptive statistics of the Meta-MEME search of SWISS protein database ${ }^{\mathrm{a}}$ using a hidden Markov model of the FoxD3 eh Ilike motif.

\begin{tabular}{lcccc}
\hline \multicolumn{1}{c}{ Protein class $^{\mathbf{b}}$} & Log-Odds $\mathbf{c}$ Mean (SD) & Log-Odds Minimum & Log-Odds Maximum & Hits ${ }^{\mathbf{d}^{\prime}}$ \\
\hline Non-Transcription & $6.87(2.24)$ & 1.49 & 24.43 & 48716 \\
Fox & $14.34(5.65)$ & 5.97 & 29.23 & 54 \\
Para-Hox & $11.61(4.83)$ & 3.64 & 23.45 & 155 \\
Other Transcription & $7.72(2.67)$ & 3.48 & 17.42 & 318 \\
All Transcription & $9.07(4.28)$ & 3.48 & 29.23 & 647
\end{tabular}

a SWISS protein database integrated in the Meta-MEME software package (version 3.2).

b Protein classes were defined by the presence of a conserved DNA-binding domain for transcriptional proteins, or by the absence of a DNAbinding domain for non-transcriptional proteins. Non-Transcription, proteins that are not members of defined families of transcriptional proteins; Fox, Fox family proteins; Para-Hox, para-Hox class of homeodomain proteins; Other Transcription, transcriptional proteins excluding Fox and para-Hox proteins; All Transcription, all transcriptional proteins.

c Log-odds score is the ratio of a sequence score with respect to the foreground model versus the sequence score with respect to the background model. The log-odds score is the logarithm of an odds score in base 2. SD, standard deviation.

d Hits are positions in the background sequence that align with a motif model.

scriptional protein classes indicated that the association of eh1-like motifs with transcriptional proteins had high statistical significance $\left(\mathrm{p}<2 \times 10^{-9}\right)$. Furthermore, analysis of the log-odds scores for the Fox family transcriptional proteins and other transcriptional protein classes were analyzed, the association of higher log-odds scores with Fox proteins was found to have high statistical significance ( $p$ $<2 \times 10^{-9}$ ). The results strongly support the conclusion that eh1 motifs are present in members of the Fox family at high frequency, and suggest that the eh1 motif contributes to the transcriptional function of many Fox family proteins.

For most of the Fox proteins analyzed, a single eh1-like motif was located C-terminal to the WHD (Fox subclasses A, B, C, D, E, H, I, L and Q). Two similar eh1-like motifs are present in the zebrafish FoxQ1 protein, with both Cterminal to the WHD. Interestingly, the C. elegans FoxD and sea urchin, amphioxus and zebrafish FoxQ2 proteins contain N-terminal eh1-like motifs, whereas a C-terminal motif location is found for the other FoxD and FoxQ orthologs. All FoxG proteins contain an eh1-like motif Nterminal to the WHD, and in sea urchin and amphioxus FoxG proteins a second eh1-like motif is located C-terminal to the WHD. The vertebrate FoxG proteins contain a C-terminal sequence that appears to be a remnant of an eh1 motif that lacks the conserved phenylalanine. Eh1like motifs were identified in Fox proteins in several early divergent species. These included sponge (phylum Porifera) FoxD, hydra and sea anemone (phylum Cnidaria) FoxA, and comb jelly (phylum Ctenophora) FoxG. The presence of eh1 motifs in Fox proteins of these phyla suggests an ancient appearance of this motif in the Fox gene family and therefore, a functional interaction with Groucho-related corepressors early in the evolution of the Fox gene family.

\section{Loss of eh I-like motifs within Fox gene subclasses}

Our sequence analysis indicates incomplete distribution of the motif within certain Fox subclasses, suggesting the loss of the motif in a subset of Fox proteins. A striking example of the loss of the eh1-like motif is observed within the FoxE subclass for FoxE1 proteins. Sequence analysis of FoxE subclass proteins did not identify a recognizable eh1 motif in seven mammalian FoxE1 proteins, whereas FoxE1 proteins of fish and amphibia, and nine other FoxE proteins contained the motif. To assess the inheritance and loss of the eh1 motif during the evolution of FoxE proteins, a phylogenetic tree for the FoxE subclass and the FoxC and FoxD outgroups was constructed using a neighbor-joining method (Figure 1). The topology of the phylogenetic tree (bootstrap value 91\%) indicates a close relatedness of the fish, amphibian, and mammalian FoxE1 proteins, which suggests a common ancestry. Therefore it is reasonable to infer that the ancestral FoxE1 protein contained the motif, and the loss of the eh1 motif occurred in the mammalian lineage or ancestors of the mammalian phyla in the course of evolution. All other members of the FoxE subclass, including the amphioxus and tunicate proteins, as well as mammalian FoxE3 proteins, contained the motif. This suggests that most likely an ancestral FoxE protein contained the motif before the separation and expansion of the FoxE subclass, and this idea is supported by the presence of the motif in nearly all members of the FoxC and FoxD outgroups.

It should be noted that a cnidarian FoxE-related protein lacks the eh1 motif, and this may be viewed as inconsistent with the presence of the eh1 motif in the ancestral FoxE protein. However, phylogenetic analysis indicates a distant relatedness of this cnidarian protein to the FoxE subclass, arguing for different origins. Similarly, the motif is not detected in the N. vectensis FoxD- and FoxC-related proteins, which also appear to have undergone significant sequence divergence. The motif is present in cnidarian 

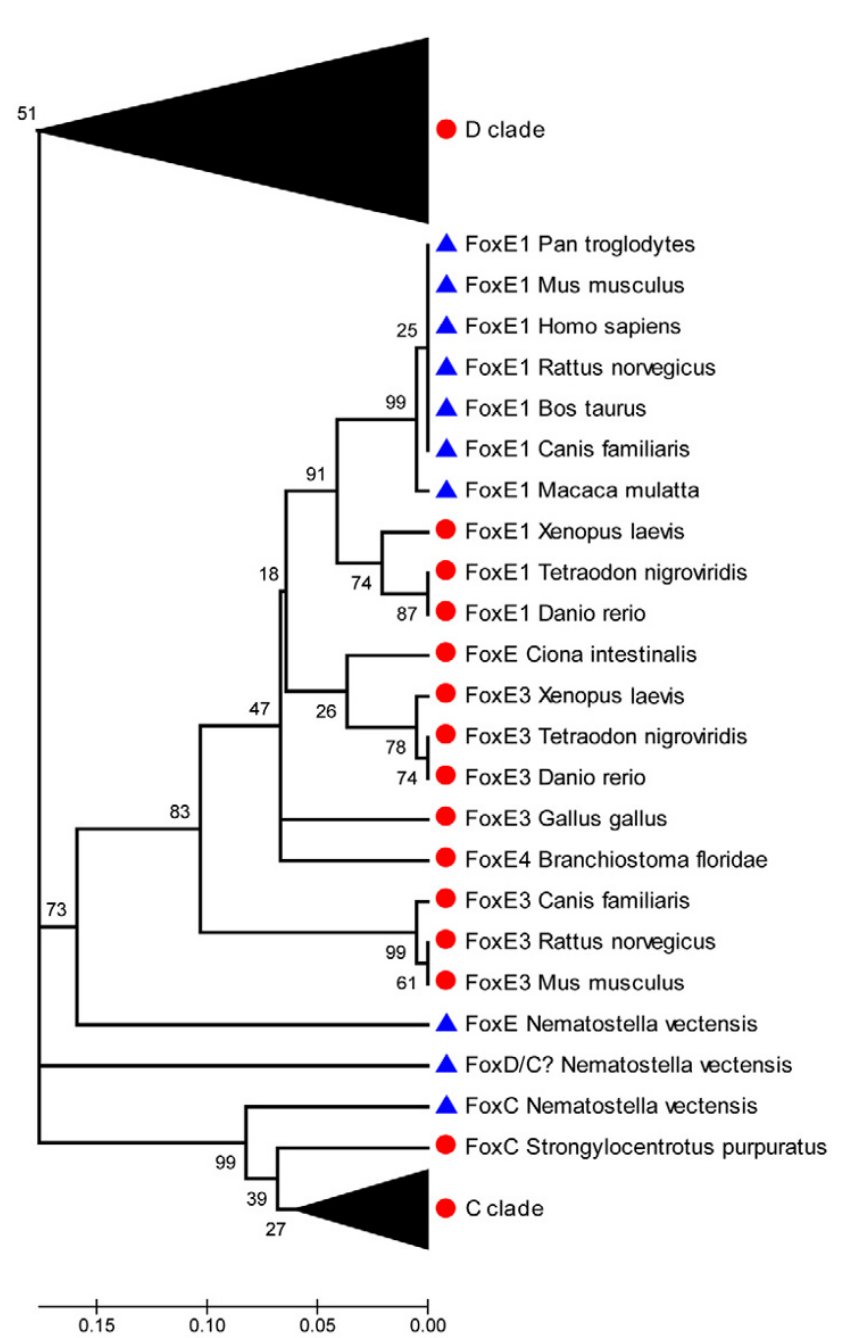

Figure I

A phylogenetic tree for proteins of the FoxE subclass and the FoxC and FoxD outgroups. A neighbor-joining method was used to construct the tree topology and bootstrapping values are shown at each branch point (percentage of 1000 bootstrap samples) using the MEGA 3.I software. Gaps were deleted in pairwise comparisons. The distance scale below the tree represents the number of substitutions per site. The $C$ and $D$ families are collapsed for better illustration. Protein sequences that lack a recognizable eh I-like motif are represented by blue triangles. Proteins and subclasses that contain an eh I-like motif are represented by red circles.

FoxA and FoxB proteins, as well as the FoxC- and FoxDrelated (Fox1) proteins of the sponge $S$. domuncula [see Additional files 1 and 2], suggesting that ancestral precursors for these subclasses contained the motif, whereas the motif was likely lost in a subset of more divergent cnidarian Fox proteins.

No eh1-like motif is detected in the tunicate FoxH-like proteins, whereas nearly all vertebrate FoxH proteins con- tain the motif. The absence of the eh1 motif in the tunicate FoxH proteins suggests a divergence and loss of this motif in the hemichordate lineage. However, it is also possible that the ancestral FoxH protein did not contain an eh1 motif and that the motif was recruited in the vertebrate lineage. Interestingly, a Xenopus FoxH1 paralog, FoxH3, also lacks the eh 1 motif present in other vertebrate FoxH orthologs, again suggesting a loss of the motif, perhaps due to functional specialization [see Additional files 1 and 2].

\section{Characteristics of eh I-like motifs in Fox family proteins}

For the eh1-like motifs identified, the amino acid frequency at each position of the motif was determined to better define the characteristics of the motif in invertebrate and vertebrate members of the Fox gene family (Figure 2). For this frequency analysis, each position in the motif is identified as 0 to 7 in an N-terminal to C-terminal order. Although this analysis includes Fox proteins of evolutionary distant organisms, similar residue usage is observed at most positions. Overall, the identified motifs are characterized by the predominance of hydrophobic residues. The aromatic residue, phenylalanine, is absolutely conserved $(100 \%)$ at position 0 of the identified motifs in vertebrates and in nearly all invertebrates. The hydrophobic core of the motif (positions 2, 5 and 6) is characterized by the frequent presence of branched hydrophobic residues such as isoleucine, leucine, methionine, and, less frequently, valine. For both vertebrates and invertebrates, isoleucine is highly represented at position $2(75 \%)$, and leucine and isoleucine appear at similar frequencies (40-60\%) at positions 5 and 6 in both invertebrates and vertebrates. Serine is highly represented at position $1(75 \%)$ in vertebrate Fox proteins, whereas serine (55\%) and threonine (30\%) predominate at this position in invertebrates. Although positions 3 and 4 are variable, there is a strong bias for negatively charged residues at position 3 and the uncharged polar residues serine and asparagine at position 4 . Position 7 of the eh1-like motifs is most variable, with glycine, alanine and serine residues often present. It should be noted that within individual Fox subclasses, residue identity at each position is more highly conserved, reflecting the evolutionary relatedness of the proteins in each subclass, as well as the conservation of subclass-specific functional and structural properties of the motifs [see Additional files 2 and 3].

The conservation of multiple hydrophobic residues in the eh 1 motif is favorable for the formation of $\alpha$-helices, and suggests that the eh1-like motifs identified in Fox family proteins have the potential to adopt a hydrophobic $\alpha$-helical structure. To predict structural characteristics of the motifs, several algorithms (DSC, PHD, MLRC) were used to calculate the propensity of secondary structure formation [26-28]. For several Fox proteins of each subclass, 

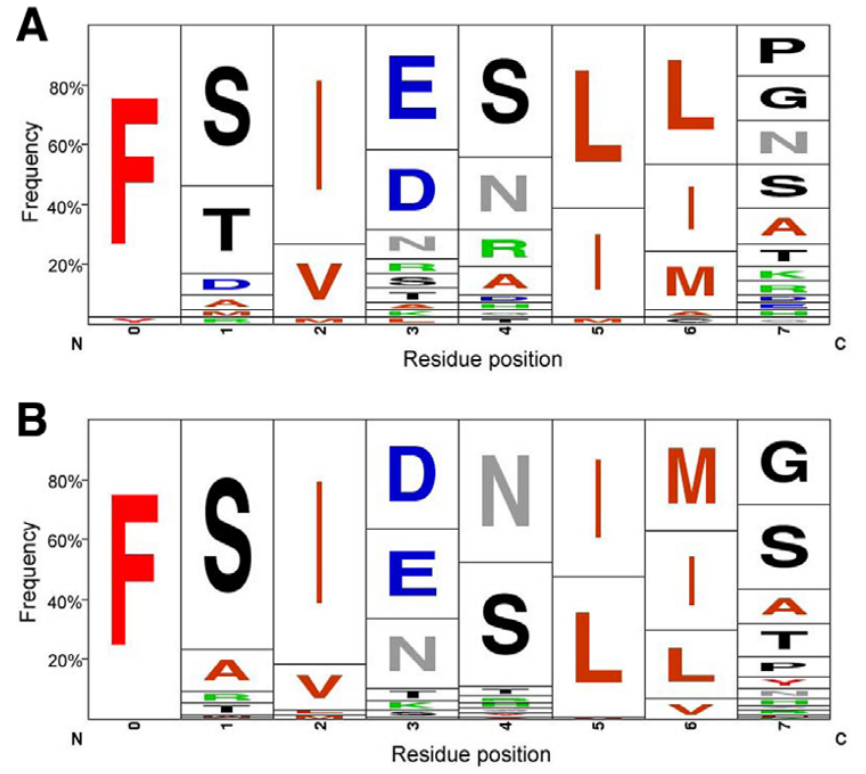

Figure 2

The diagrams summarize the amino acid compositions of the eh I-like motifs identified in Fox proteins. The amino acid usage frequency of eh I-like motifs identified in invertebrate (A) and vertebrate (B) Fox proteins. The diagrams were generated with the WebLogo program [44].

regions containing the eh1-like motif were analyzed for predicted secondary structure. The results obtained using multiple algorithms predict a high likelihood of $\alpha$-helical structure in the region of the eh1-like motif for the majority of Fox proteins examined. The highest scores for $\alpha$-helical propensity were obtained for the eh1-like motifs present in FoxB, FoxE and FoxQ proteins, and $\alpha$-helical structure was also predicted for FoxD, FoxA, FoxC and FoxL proteins, albeit with lower propensity scores [see Additional file 4 and data not shown].

In BLAST searches, the eh1-like motifs of several Fox proteins, including FoxB and FoxE proteins, show similarity to the hydrophobic regions of several membrane proteins, including the $\alpha$-helical regions of the Chlorobium tepidum segregation and condensation protein B (CHPfCT, AAM71720), Pseudomonas aeruginosa probable transcriptional regulator Pa0477 (2ESND), and Drosophila ultraspiracle ligand-binding domain (ULBD, 1HG4F) (Figure 3A and data not shown). A BLAST search for sequences related to the $N$. vectensis Fox1 eh1-like motif identified the $\alpha$-helical region of Hepatitis C RNA Polymerase (1YVZA) as the only related sequence (Figure $3 \mathrm{~B}$ ). The ability of eh1-like sequences in proteins unrelated to the Fox family to form $\alpha$-helical structure supports the prediction of $\alpha$-helical structure for the eh1-like motifs identified in Fox proteins.
Helical wheel analysis of the predicted $\alpha$-helical regions of the eh1-like motifs revealed an amphipathicity for a majority of the identified motifs. As an example of this analysis, the helical wheel models of the eh1-like motifs of FoxB1 and FoxE4 (Figure 3C,D) display a predicted amphipathicity of the $\alpha$-helical structure. For both eh1like motifs, a hydrophobic surface is formed by Isoleucine residues at positions 2, 5 and 6 of the predicted $\alpha$-helix. The eh1-like motifs of a subset of FoxB1, FoxB2, FoxH1 and FoxQ1 proteins contain an additional hydrophobic residue (Alanine or Methionine) at position 1 that extends the hydrophobic surface of the predicted $\alpha$-helix (Figure 3C and data not shown). Opposite the hydrophobic surface of the predicted $\alpha$-helix is a surface consisting predominantly of hydrophilic and non-charged residues (Figure 3C,D and data not shown). Thus, the majority of the eh1-like motifs identified in Fox proteins have a predicted amphipathic $\alpha$-helical structure. The validity of the predicted eh1 structure is strongly supported by a recent crystallographic study showing that the Goosecoid eh1 motif forms a short amphipathic $\alpha$-helix when bound to the WD domain of TLE1 [29].

\section{Positional distribution of C-terminal eh I-like motifs}

The eh1-like motifs identified in the Fox family were further analyzed for motif position within individual Fox proteins. Given that nearly all of the eh1-like motifs identified in the Fox family are positioned C-terminal to the WHD, we limited the analysis to C-terminal motifs. To assess the variation in motif position within the $\mathrm{C}$-terminus of Fox proteins, the positional distribution of the eh1like motifs relative to the WHD was examined. A substantial variation in the relative positions of the C-terminal eh1-like motifs and the WHDs was found, with an interval ranging from 30-180 residues (Figure 4). A detailed analysis of the positional distribution of these domains in 89 Fox protein sequences revealed two groups, C-proximal and C-distal, defined by maximum interval occurrence between the two domains. For the C-proximal eh1 motifs the maximum interval occurrence is 45-60 residues with a median value of 58 residues (Figure $4 \mathrm{~A}$ ). For the C-distal motifs the maximum interval occurrence is $100-140$ residues with a median value of 120 residues (Figure 4B).

Positional variation of the C-terminal eh1-like motifs was also examined within Fox ortholog and paralog groups for eight subclasses. This analysis was limited to chordate Fox proteins as non-chordates lack many Fox subclasses. Proteins of Fox subclasses B, E, H and Q contain C-proximal motifs, whereas C-distal motifs are present in Fox subclasses A, C, D and I. The positional distribution of the motifs in the ortholog groups is shown in Figure 5. The analysis indicates that the position of eh1-like motifs is conserved within individual Fox protein subclasses across species, but not across subclasses within individual spe- 

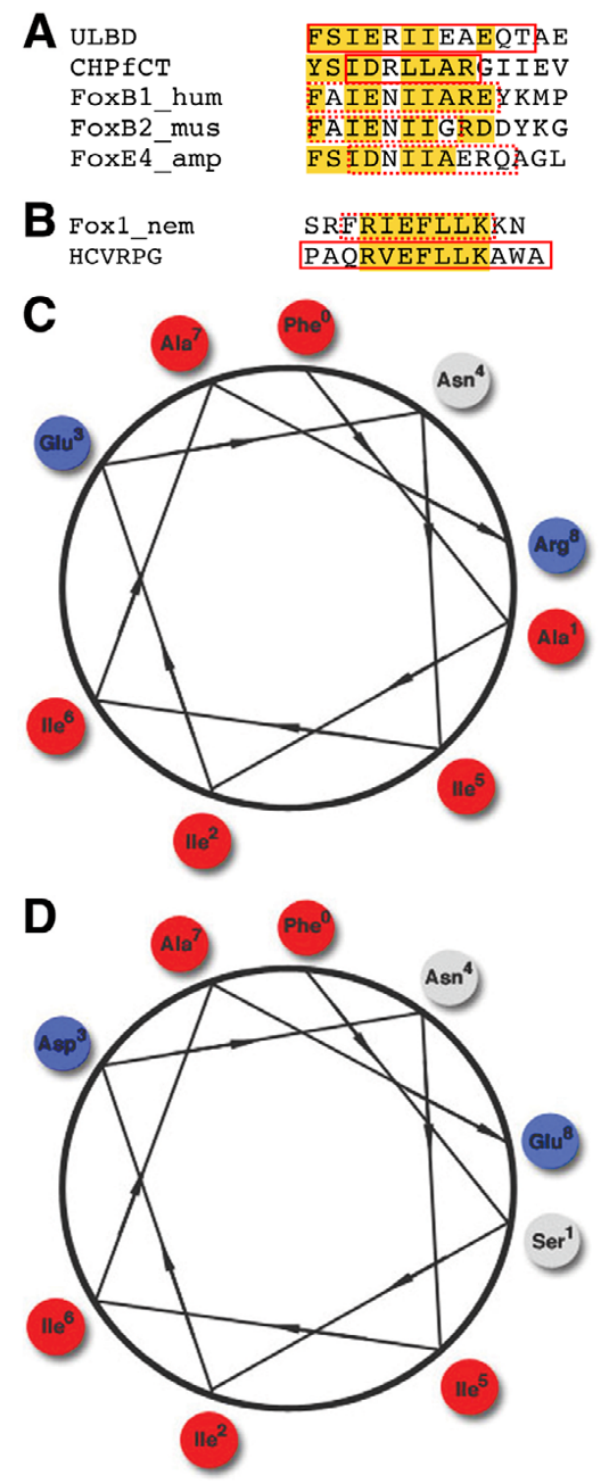

Figure 3

(A) Multiple sequence alignments of the $\alpha$-helical region of an ultraspiracle ligand binding domain from Drosophila (ULBD), $\alpha$-helix of a conserved hypothetical protein from $C$. tepidum (CHPfCT), and the eh I motifs of human FoxBI, murine FoxB2 and amphioxus FoxE4 proteins, which have a high likelihood of $\alpha$-helix formation. (B) Sequence alignment for the $\alpha$-helical region of the Hepatitis C Virus RNA Polymerase Genotype 2a (HCVRPG) and the eh I motif of the cnidarian Foxl protein. The defined $\alpha$-helices are represented as red solid boxes and predicted $\alpha$-helices are shown as red dotted boxes. Amino acid similarities are shown in yellow. hum, Human; mus, Mouse; amp, amphioxus; nem, Sea Anemone. Wheel models of the eh I-like motifs of Xenopus FoxBI (C) and amphioxus FoxE4 (D) form an amphipathic $\alpha$-helical structure. Hydrophobic residues on the wheel are shown in the red, hydrophilic residues are shown in the blue, and noncharged residues are shown in the gray.
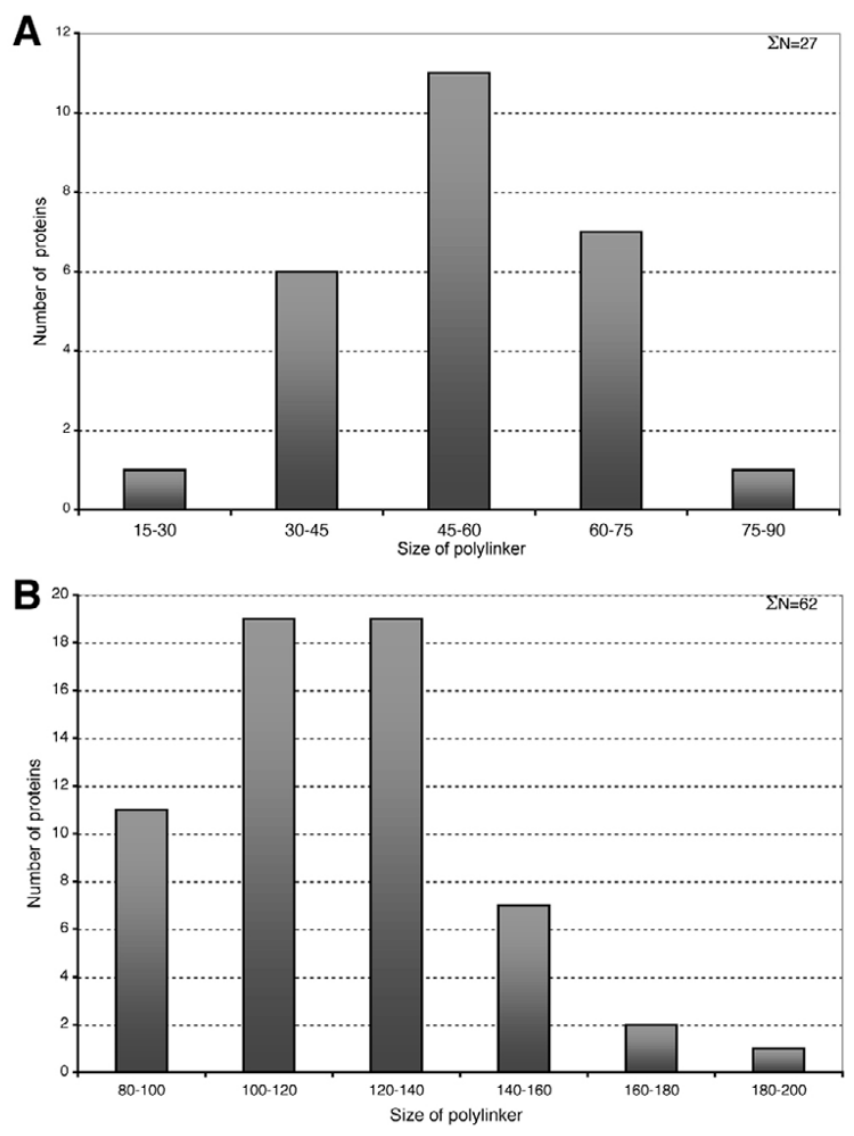

Figure 4

The positional distribution of the C-terminal eh I-like motifs in Fox proteins of the $B, E, H$ and $Q$ subclasses $(A)$ and the $A$ $D, C$ and I subclasses (B). Size of polylinker represents the distance between the first residue of the eh I motif and the conserved C-terminal residue of the winged helix DNA-binding domain.

cies. This conservation of motif position within each subclass is consistent with the existence of a common ancestral gene for the Fox genes comprising an individual subclass [17], but may also reflect a functional constraint that maintains the position of the eh1 motif. Exceptions to the conservation of motif position are observed for the FoxD and FoxQ subclasses, and for orthologs of FoxA3, FoxC1, and FoxH1. For the FoxD subclass, a shift of motif position towards the C-terminus is observed for chick, mouse and human proteins, when compared to amphixous, zebrafish and Xenopus (Figure 5A). A C-terminal shift is also observed for the eh1 motifs of Xenopus, mouse and human FoxQ proteins, compared to amphioxus and zebrafish (Figure 5B). Similarly, for FoxC1 proteins, the eh1 motif of the chick and mammalian orthologs is shifted C-terminally in comparison to the zebrafish and Xenopus orthologs. In contrast, the eh1 motif of mammalian FoxH1 proteins is shifted N-terminally, closer to the 

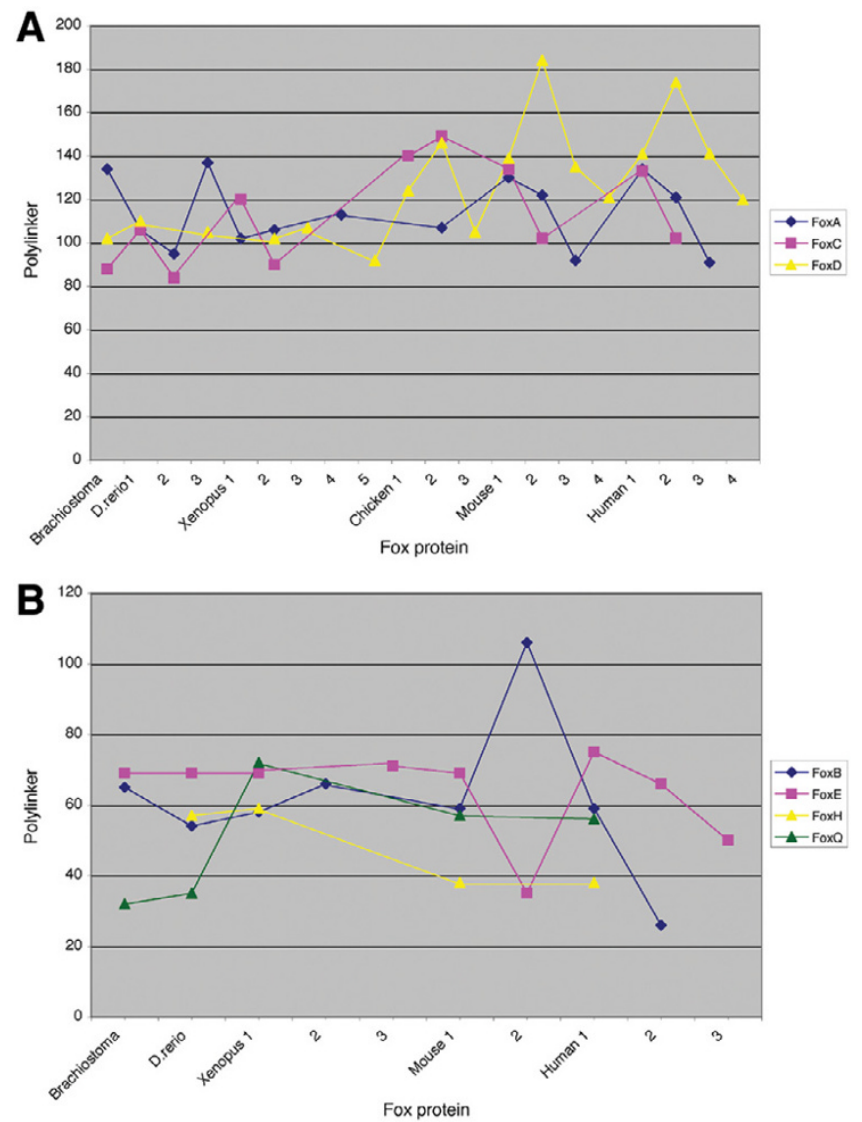

Figure 5

Positional fluctuations of eh I-like motifs in the ortholog and paralog groups of vertebrate Fox proteins. (A) Positional fluctuations of the ehI-like motifs of the ortholog and paralog groups of the A, C and D subclasses. (B) Positional fluctuations of the eh I-like motifs of the ortholog and paralog groups of the $\mathrm{B}, \mathrm{E}, \mathrm{H}$ and $\mathrm{Q}$ subclasses. Polylinker represents the distance between the first residue of the eh I-like motif and the conserved $\mathrm{C}$-terminal residue of the winged helix DNA-binding domain. The paralog groups within a Fox subclass are indicated on the $x$-axis.

WHD, in comparison to the zebrafish and Xenopus proteins.

For each case where eh1 motif position is not conserved, the shift in motif position correlates with changes in the size of the coding region C-terminal to the WHD. For example, sequence alignment of FoxD subclass proteins reveals the presence of polyalanine, polyglycine and polyproline repeats in the mammalian proteins that are absent in FoxD proteins of lower vertebrates (data not shown). On the other hand, mammalian FoxH1 proteins lack sequences C-terminal to the WHD that are present in the Xenopus and zebrafish orthologs (data not shown). Thus, insertion or deletion of sequences within the C-terminal domain of these mammalian Fox proteins is likely responsible for the shift of eh1 motif position.

\section{Discussion}

In this study, we have identified the presence of eh1-like Groucho interaction motifs in ten subclasses of the Fox family of transcriptional regulators by systematically analyzing 458 protein sequences of nineteen Fox subclasses. The analysis shows a widespread distribution of eh1-like motifs within the Fox protein family. The presence of the motif was identified in Fox subclasses, A, B, C, D, E, G, H, $\mathrm{I}, \mathrm{L}$ and $\mathrm{Q}$, and no eh1-like motif was detected in proteins of the F, J, K, M, N, O, P, R and S subclasses. The majority of the eh1-like motifs identified were located C-terminal to the WHD, including proteins of nine Fox subclasses (A, B, C, D, E, H, I, L and Q). Only the FoxG subclass proteins contained eh1-like motifs N-terminal in the WHD. For Fox proteins containing C-terminal eh1-like motifs, the position of the motif relative to the WHD defined a Cproximal group with motifs $45-60$ residues from the WHD (Fox subclasses B, E, H and Q) and a C-distal group with motifs 100-140 residues from the WHD (Fox subclasses A, C, D and I). The presence of eh1 motifs in more than $50 \%$ of Fox family proteins was in marked contrast to other protein families, including both transcriptional and non-transcriptional proteins (Table 4 and data not shown).

The prevalence of eh1-like motifs in the Fox family suggests that Groucho corepressors directly interact with many Fox proteins to mediate transcriptional repression activity or to inhibit the activation function of other regulatory domains. In a number of cases the functional importance of the identified eh1-like motifs is confirmed by the presence of the motifs within defined transcriptional repression domains and by the ability to mediate direct binding to Groucho proteins. The eh1 motifs are present in the C-terminal repression domains of mouse and chick FoxD3 [30,31], and Xenopus FoxD5 [32], as well as the C-terminal transcriptional inhibitory domain of mouse FoxC1 [33]. Furthermore, the eh1 motifs mediate a functional and direct interaction with Groucho corepressors in mouse FoxA2 [19], Drosophila FoxG/sloppypaired-1 [20], mouse FoxG1 [34], and Xenopus FoxD3 [21] and FoxH1 (SY and DSK, unpublished). These results confirm the importance of eh 1 motifs in Fox family proteins, and suggest that the eh1-like motifs identified in this study may mediate a previously unappreciated interaction of Groucho corepressors with many Fox proteins.

Secondary structure analysis of the eh1-like motifs indicates that a majority of the identified motifs are highly likely to form an $\alpha$-helical structure. In support of this secondary structure prediction, a number of the eh1-like motifs exhibit sequence similarity to regions of unrelated 
proteins with known $\alpha$-helical structure. In addition, the eh1-like motifs exhibit amphipathicity, which argues in favor of $\alpha$-helix formation by the motifs. Structural studies of a number of transcriptional regulators have demonstrated the importance of amphipathic $\alpha$-helices in binding to transcriptional coregulators. The p53 tumor suppressor binds to the transcriptional coactivator, MDM2, via a 13 amino acid motif. Structural studies have shown that the MDM2 interaction motif of p53 forms an amphipathic $\alpha$-helix that binds to MDM2 through hydrophobic interactions [35]. In addition, NRSF/REST binds to the Sin3 corepressor via several short amphipathic or hydrophobic $\alpha$-helices [3]. Therefore, the predicted amphipathic $\alpha$-helical structure of the eh 1 motifs is likely an essential feature for direct, high-affinity binding of Fox proteins to Groucho corepressors. This conclusion is strongly corroborated by recent structural studies showing that the eh1 motif present in the human Goosecoid protein forms a short amphipathic $\alpha$-helix when bound to the WD domain of the Groucho family protein TLE1 [29]. In general, these observations support the idea that diverse families of transcriptional regulators utilize distinct conserved motifs, which adopt a common amphipathic $\alpha$-helical structure, as adaptors for the physical interaction with transcriptional coregulators.

Eh1-like motifs were identified in Fox proteins of the most evolutionary ancient organisms, including marine sponge (porifera), comb jelly (ctenophora) and sea anemone (cnidaria). The presence of the eh1-like motif in Fox proteins of these organisms likely reflects the presence of the eh1-Groucho interaction functional module early in evolutionary history. Eh1-like motifs are also present in other transcriptional regulators of the sponge, including the Barx/Bsh1 (AAQ24371) and a paraHox-related homeodomain protein (CAD37941). Consistent with the presence of eh1-like motifs in transcriptional regulatory proteins of early divergent species, a Groucho gene (CN626783) has been identified in the cnidarian Hydra. These data suggest an ancient origin for eh 1 motif-dependent recruitment of Groucho corepressors, a protein interaction that may have been established as early as the porifera.

An intriguing question raised by these analyses is the origins of the eh 1 motifs in the Fox gene family. The motifs identified in all Fox subclasses, except for the FoxG subclass, are positioned C-terminal to the WHD. The occurrence of the eh1-like motif $\mathrm{N}$-terminal to the WHD in the FoxG subclass and FoxQ2 suggests that the N-terminal motif may have arisen independent of the C-terminal motif. In addition, two eh1-like motifs, positioned N-terminal and C-terminal to the WHD, were identified in the sea urchin and amphioxus FoxG1 proteins. The presence of two motifs in distinct regions of a subset of FoxG1 orthologs is consistent with independent origins for the
C-terminal and N-terminal eh1 motifs. Given the small size of the eh1 motif ( 8 residues), it is possible that the motif arose multiple times in the Fox family. Therefore, the formation of new eh1-like motifs through the accumulation of missense mutations offers a convergent mechanism for multiple independent appearances of the motif in the Fox family. Alternatively, the Fox genes may have acquired the motif via a non-homologous recombination event that introduced a repression module containing an eh1-like motif. Such a scenario could involve the incorporation of a new exon encoding the repression module. However, since a majority of the Fox family genes lack introns, this mechanism would require intron loss subsequent to incorporation of the eh1-encoding exon.

An apparent loss of eh1 motifs was observed in a subset of FoxD, FoxE, and FoxH proteins. Our analysis indicates that the loss of the motif occurred in a subset of mammalian Fox proteins and we speculate that the motif loss provided a new functional modification for these proteins that was evolutionarily beneficial. Since the presence of an eh1 motif likely mediates a functional interaction with Groucho corepressors, the loss of the motif may represent an alteration of both transcriptional activity and regulatory function for individual Fox proteins. For example, while FoxH1 proteins can function as transcriptional activators or repressors by recruitment of Smad coactivators or Groucho corepressors [36,37] (SY and DSK, unpublished), it is predicted that FoxH3 functions exclusively as an activator in association with Smad coactivators [38]. Thus, the eh1 motif may play an important role in the evolution of the Fox gene family by providing a basis for the evolutionary modification of Fox protein function.

\section{Conclusion}

The identification of eh1-like motifs in many members of the Fox gene family provides an important insight into the potential transcriptional activity of Fox family proteins, and provides a foundation for the study of eh 1 motif function in the Fox family. Biochemical and transcriptional studies will now be necessary to determine if the identified eh1-like motifs mediate a direct physical interaction with Groucho corepressors to confer transcriptional repression activity. Building on our motif analyses, ongoing functional studies should yield a more comprehensive understanding of the evolution, domain organization, and transcriptional activity of the Fox gene family.

\section{Methods}

\section{Manual sequence analysis}

The Fox gene family is subdivided into nineteen subclasses on the basis of homology within the winged helix DNA-binding domain [15], and at the time of this study the nineteen subclasses comprised 458 sequences. To 
identify eh1-like motifs, we used the eh1 consensus sequence $\mathrm{F}^{0} \mathrm{~S} / \mathrm{A}^{+1} \Phi^{+2} \mathrm{X}^{+3} \mathrm{X}^{+4} \Phi^{+5} \Phi^{+6} \mathrm{X}^{+7} \quad(\Phi$, branched hydrophobic residues; $\mathrm{X}$, non-polar or charged residues), which has been generated based on the published data. Yeast and metazoan Fox protein sequences present in the SWISS-PROT and NCBI databases were analyzed. To identify the presence of an eh1-like motif in protein sequences of the nineteen subclasses, we performed PSI-BLAST searches of the non-redundant databases with inclusion threshold (E-value) of 0.01 using members of each Fox subclass as a query. In parallel, the sequences of all subclasses were retrieved from the NCBI database and multiple protein alignments were constructed for each subclass using the CLUSTAL W algorithm in the software package MacVector 7.2.2. Regions that were conserved within either the $\mathrm{N}$-terminal or C-terminal regions of at least two species were examined for a minimum of $50 \%$ similarity to the eh1 consensus. Taken together these searches allowed for the identification of conserved sequences matching the eh1 consensus in ten Fox subclasses.

\section{Expectation-maximization and hidden Markov model analyses}

The expectation-maximization algorithm of the MEME program (Multiple Em for Motif Elicitation, version 3.5.4) $[22,39]$ was used to analyze 458 proteins of the Fox family for the presence of eh1-like motifs. The search parameters used were 20-30 motifs per a run and a motif size of 810 amino acid residues.

An eh1 motif position-specific probability matrix was generated for a set of FoxD3 protein sequences using MEME, and this matrix was used to construct a hidden Markov model for eh1-like motifs using the Meta-MEME program (Motif-based hidden Markov modeling of biological sequences, version 3.2) $[24,40]$. The SWISS protein database was searched with the FoxD3 eh1-like motif model using an E-value threshold of $<10^{4}$ for reported sequences.

Logistic regression analysis was performed to determine whether there was a statistically significant correlation between the results of the hidden Markov model analysis (log-odds scores) and all transcriptional proteins or Fox family proteins specifically. The dependent variable in the logistic regression analysis is the dummy variable $(y)$, which is equal to 1 when a transcriptional protein is present and 0 otherwise. The independent variable is the score $(x)$. The estimated logistic regression equation is: $\hat{y}=\frac{e^{a+b x}}{1+e^{a+b x}}$, where $x$ is the score and $\hat{y}$ is an estimate of the probability that $y=1$ or that the transcription factor is present given the score.

\section{Phylogenic analysis of Fox proteins}

A phylogenic tree for the FoxE subclass was generated based on the winged-helix DNA-binding domain sequences (100 residues) for FoxC, FoxD and FoxE subclass proteins. Multiple sequence alignments were constructed using Clustal W [41] and these sequences were converted into a cladogram using MEGA 3.1 [42]. Distances were calculated with Poisson correction, and a neighbor-joining method was used to construct the tree topology with bootstrap analysis of 1000 samples.

\section{Secondary structure analysis}

For secondary structure predictions, the C-terminal or Nterminal domain of selected Fox proteins of each subclass was subjected to analysis using algorithms that predict secondary structure with accuracy in the range of $0.67-$ 0.7. The prediction algorithm is available at the Network Protein Sequence Analysis website [43]. The source code of the combiner can be obtained on request for academic use. In addition, software written by M.L. (unpublished) was used to predict the secondary structure of Fox protein sequences. This helix prediction algorithm is based on all high-resolution structures available, with the scoring function comparing homology of the sequences to known helical structures.

\section{Authors' contributions}

SY initiated these studies and was involved in all aspects of the design, execution and interpretation of these studies, as well as the writing of the manuscript. AV participated in the motif search and statistical analyses, and contributed to the writing of the manuscript. SS and ML contributed to the secondary structure analysis and amphipathic modeling. DSK contributed to the design and interpretation of these studies, data presentation and writing of the manuscript. All authors read and approved the final manuscript.

\section{Additional material}

\section{Additional file 1}

Phylogenetic Tree of the Fox Gene Family Indicating the Occurrence of eh1 Motifs. A phylogenetic tree of the entire Fox gene family indicating which individual proteins contain an eh1-like motif.

Click here for file

[http://www.biomedcentral.com/content/supplementary/14712164-8-201-S1.jpeg]

\section{Additional file 2}

Legends for Additional Files 1 and 3. Description of data presented in Additional Files 1 and 3.

Click here for file

[http://www.biomedcentral.com/content/supplementary/14712164-8-201-S2.doc] 


\section{Additional file 3}

The amino acid composition of eh1-like motifs identified in individual Fox protein subclasses. Diagrams representing the amino acid composition of the eh1-like motifs identified in each Fox family subclass of invertebrate and vertebrate organisms.

Click here for file

[http://www.biomedcentral.com/content/supplementary/14712164-8-201-S3.tiff]

\section{Additional file 4}

Propensity for $\alpha$-helix formation for eh1-like motifs in selected Fox proteins. An analysis of the propensity for $\alpha$-helix formation at the position of individual residues within the eh1-like motifs of selected Fox family proteins

Click here for file

[http://www.biomedcentral.com/content/supplementary/14712164-8-201-S4.doc]

\section{Acknowledgements}

We thank Brian Brunk for critical reading of the manuscript. This work was supported by a grant from the NIH (GM64768) to D.S.K.

\section{References}

I. Courey AJ, Jia S: Transcriptional repression: the long and the short of it. Genes Dev 200I, 15(21):2786-2796.

2. Hanna-Rose W, Hansen U: Active repression mechanisms of eukaryotic transcription repressors. Trends Genet 1996, I 2(6):229-234.

3. Nomura M, Uda-Tochio H, Murai K, Mori N, Nishimura Y: The neural repressor NRSF/REST binds the PAHI domain of the Sin 3 corepressor by using its distinct short hydrophobic helix. J Mol Biol 2005, 354(4):903-915.

4. Chen G, Courey AJ: Groucho/TLE family proteins and transcriptional repression. Gene 2000, 249(I-2):I-16.

5. Jimenez G, Verriizer CP, Ish-Horowicz D: A conserved motif in goosecoid mediates groucho-dependent repression in Drosophila embryos. Mol Cell Biol 1999, 19(3):2080-2087.

6. Logan C, Hanks MC, Noble-Topham S, Nallainathan D, Provart NJ, Joyner AL: Cloning and sequence comparison of the mouse, human, and chicken engrailed genes reveal potential functional domains and regulatory regions. Dev Genet 1992, 13(5):345-358.

7. Smith ST, Jaynes JB: A conserved region of engrailed, shared among all en-, gsc-, Nkl-, Nk2- and msh-class homeoproteins, mediates active transcriptional repression in vivo. Development 1996, I 22(10):314|-3150.

8. Tolkunova EN, Fujioka M, Kobayashi M, Deka D, Jaynes JB: Two distinct types of repression domain in engrailed: one interacts with the groucho corepressor and is preferentially active on integrated target genes. Mol Cell Biol 1998, 18(5):2804-28I4.

9. Muhr J, Andersson E, Persson M, Jessell TM, Ericson J: Grouchomediated transcriptional repression establishes progenitor cell pattern and neuronal fate in the ventral neural tube. Cell 200I, I04(6):86I-873.

10. Williams NA, Holland PW: An amphioxus Emx homeobox gene reveals duplication during vertebrate evolution. Mol Biol Evol 2000, I7(10):1520-1528.

II. Lopez-Rios J, Tessmar K, Loosli F, Wittbrodt J, Bovolenta P: Six 3 and Six6 activity is modulated by members of the groucho family. Development 2003, I30(I): 185-195.

12. Shimeld SM: A transcriptional modification motif encoded by homeobox and fork head genes. FEBS Lett 1997, 410(23): $124-125$.

13. Carlsson P, Mahlapuu M: Forkhead transcription factors: key players in development and metabolism. Dev Biol 2002, 250(I): $1-23$.
14. Clark KL, Halay ED, Lai E, Burley SK: Co-crystal structure of the HNF-3/fork head DNA-recognition motif resembles histone H5. Nature 1993, 364(6436):412-420.

15. Kaestner KH, Knochel W, Martinez DE: Unified nomenclature for the winged helix/forkhead transcription factors. Genes Dev 2000, I 4(2): I 42-146.

16. Katoh M, Katoh M: Human FOX gene family. Int J Oncol 2004, 25(5): $1495-1500$.

17. Mazet F, Yu JK, Liberles DA, Holland LZ, Shimeld SM: Phylogenetic relationships of the Fox (Forkhead) gene family in the Bilateria. Gene 2003, 316:79-89.

18. Winged Helix Proteins [http://www.biology.pomona.edu/ fox.html]

19. Wang JC, Waltner-Law M, Yamada K, Osawa H, Stifani S, Granner DK: Transducin-like enhancer of split proteins, the human homologs of Drosophila groucho, interact with hepatic nuclear factor 3beta. J Biol Chem 2000, 275(24): 18418-| 8423 .

20. Andrioli LP, Oberstein AL, Corado MS, Yu D, Small S: Grouchodependent repression by sloppy-paired I differentially positions anterior pair-rule stripes in the Drosophila embryo. Dev Biol 2004, 276(2):54I-55I.

21. Yaklichkin S, Steiner AB, Lu Q, Kessler DS: FoxD3 and Grg4 physically interact to repress transcription and induce mesoderm in Xenopus. J Biol Chem 2007, 282(4):2548-2557.

22. Bailey TL, Elkan C: Fitting a mixture model by expectation maximization to discover motifs in biopolymers. Proc Int Conf Intell Syst Mol Biol 1994, 2:28-36.

23. Copley RR: The EHI motif in metazoan transcription factors. BMC Genomics 2005, 6:169.

24. Grundy WN, Bailey TL, Elkan CP, Baker ME: Meta-MEME: motifbased hidden Markov models of protein families. Comput Appl Biosci 1997, I3(4):397-406.

25. Garcia-Fernandez J: Hox, ParaHox, ProtoHox: facts and guesses. Heredity 2005, 94(2): I 45- I52.

26. Guermeur Y, Geourjon C, Gallinari P, Deleage G: Improved performance in protein secondary structure prediction by inhomogeneous score combination. Bioinformatics 1999, I5(5):4|3-42|.

27. King RD, Saqi M, Sayle R, Sternberg MJ: DSC: public domain protein secondary structure predication. Comput Appl Biosci 1997, I3(4):473-474.

28. Rost B, Sander C, Schneider R: PHD--an automatic mail server for protein secondary structure prediction. Comput Appl Biosci 1994, I0(1):53-60.

29. Jennings BH, Pickles LM, Wainwright SM, Roe SM, Pearl LH, IshHorowicz D: Molecular recognition of transcriptional repressor motifs by the WD domain of the Groucho/TLE corepressor. Mol Cell 2006, 22(5):645-655.

30. Freyaldenhoven BS, Freyaldenhoven MP, lacovoni JS, Vogt PK: Avian winged helix proteins $\mathrm{CWH}-\mathrm{I}, \mathrm{CWH}-2$ and $\mathrm{CWH}-3$ repress transcription from Qin binding sites. Oncogene 1997, I5(4):483-488.

31. Sutton J, Costa R, Klug M, Field L, Xu D, Largaespada DA, Fletcher CF, Jenkins NA, Copeland NG, Klemsz M, Hromas R: Genesis, a winged helix transcriptional repressor with expression restricted to embryonic stem cells. J Biol Chem 1996, 27I (38):23I 26-23I33.

32. Sullivan SA, Akers L, Moody SA: foxD5a, a Xenopus winged helix gene, maintains an immature neural ectoderm via transcriptional repression that is dependent on the C-terminal domain. Dev Biol 200I, 232(2):439-457.

33. Berry FB, Saleem RA, Walter MA: FOXCI transcriptional regulation is mediated by $\mathrm{N}$ - and $\mathrm{C}$-terminal activation domains and contains a phosphorylated transcriptional inhibitory domain. J Biol Chem 2002, 277( I 2): 10292-10297.

34. Yao J, Lai E, Stifani S: The winged-helix protein brain factor I interacts with groucho and hes proteins to repress transcription. Mol Cell Biol 200I, 2 I (6): I $962-1972$.

35. Kussie PH, Gorina S, Marechal V, Elenbaas B, Moreau J, Levine AJ, Pavletich NP: Structure of the MDM2 oncoprotein bound to the p53 tumor suppressor transactivation domain. Science 1996, 274(5289):948-953.

36. Kofron M, Puck H, Standley H, Wylie C, Old R, Whitman M, Heasman $\mathrm{J}$ : New roles for FoxHI in patterning the early embryo. Development 2004, I 3 I (20):5065-5078. 
37. Stemple DL: Vertebrate development: the fast track to nodal signalling. Curr Biol 2000, I0(22):R843-6.

38. Howell M, Inman GJ, Hill CS: A novel Xenopus Smad-interacting forkhead transcription factor (XFast-3) cooperates with XFast- $I$ in regulating gastrulation movements. Development 2002, I 29( ( 2):2823-2834.

39. The MEME/MAST System [http://meme.sdsc.edu/meme]

40. Meta-MEME [http://metameme.sdsc.edu]

41. Higgins DG, Thompson JD, Gibson TJ: Using CLUSTAL for multiple sequence alignments. Methods Enzymol 1996, 266:383-402.

42. Kumar S, Tamura K, Nei M: MEGA3: Integrated software for Molecular Evolutionary Genetics Analysis and sequence alignment. Brief Bioinform 2004, 5(2): 150-163.

43. Pole Biolnformatique Lyonnais [http://pbil.ibcp.fr/NPSA/
(n) npsa server.html]

44. Crooks GE, Hon G, Chandonia JM, Brenner SE: WebLogo: a sequence logo generator. Genome Res 2004, I 4(6): I I 88-I I 90.

Publish with Bio Med Central and every scientist can read your work free of charge

"BioMed Central will be the most significant development for disseminating the results of biomedical research in our lifetime. "

Sir Paul Nurse, Cancer Research UK

Your research papers will be:

- available free of charge to the entire biomedical community

- peer reviewed and published immediately upon acceptance

- cited in PubMed and archived on PubMed Central

- yours - you keep the copyright

Submit your manuscript here:

http://www.biomedcentral.com/info/publishing_adv.asp
BioMedcentral 